\title{
Effect of Applying Shoulder Exercises on Shoulder Function after Modified Radical Mastectomy
}

\section{Eman M. Ahmed, Mimi M. Mekkawy \& Ahmed Awad Sayed.}

Assistant lecturer of Medical-Surgical Nursing, Faculty of Nursing, Beni-Sueif University, Egypt. Professor of Medical-Surgical Nursing, Faculty of Nursing, Assiut University, Egypt.

Assistant Professor of Surgical oncology, South Egypt Cancer Institute, Assiut University, Egypt.

\begin{abstract}
Aim of study: was to identify the effect of applying shoulder exercises on shoulder function after modified radical mastectomy. Research design: Quasi-experimental design was utilized. Setting: data were collected from the surgical oncology department and surgical outpatient clinic at South Egypt Cancer Institute - Assiut University. Subjects: The study was conducted on (80) adult female patients with breast cancer scheduled for modified radical mastectomy and were randomly and alternatively divided equally into study and control groups; (40) for each. Tools: data were collected using three tools: Tool (I): Structured Interview Questionnaire; including two parts, tool (II): Shoulder range of motion assessment questionnaire and tool (III): Shoulder functional ability assessment questionnaire. Results: More than half of women in both groups, their ages ranged between (40 - 60) years with mean ages $(45.5 \pm 11.7)$ for the study group \& $(44.8 \pm 10.8)$ for the control group. Majority of the study group had normal shoulder function while most of the control group had difficulty in shoulder function $(80 \%$ \& 60\%) respectively one month after exercise. Conclusion: Utilizing post mastectomy shoulder exercises significantly improves shoulder function and shoulder range of motion for patients undergoing modified radical mastectomy. Recommendations: Increase level of awareness among patients regarding shoulder exercises.
\end{abstract}

\section{Keywords: Breast Cancer, Modified Radical Mastectomy, Shoulder Exercises \& Range of Motion.}

\section{Introduction}

Breast cancer is usually treated by surgery, which may be followed by chemotherapy or radiation therapy or both. A multidisciplinary approach is preferable. Mastectomy is a surgery to remove one or both breasts; there are many types of mastectomy, such as simple mastectomy, subcutaneous mastectomy, skin-sparing mastectomy, nipple-sparing mastectomy, radical mastectomy and modified radical mastectomy (Saini, et al., 2011 and Williams \& Hopper, 2011).

Modified radical mastectomy is the most common treatment of invasive breast cancer and it is the removal of all breast tissue from the affected breast with removal of lymph nodes from the armpit in the affected side of the body. This surgery includes the removal of both nipples and areola (Shaaban, 2013). Many complications may occur after modified radical mastectomy such as restricted shoulder mobility, shoulder dysfunction, wound infection, stiffness, seroma formation, pain and lymphedema (Bahgat, et al., 2016).

Worldwide, breast cancer is the most common invasive cancer in women. It affects about $12 \%$ of women around the world (McGuire, et al., 2015). The American Cancer Society's estimates of breast cancer in the United States in 2015 for about 231,840 new cases of invasive breast cancer and about 40,290 women would die from it (American Cancer Society, 2015).

In a recent epidemiological study in the Egyptian cancer institute, breast cancer represented $35.1 \%$ of the total female cancer cases in Egypt (Faisal, et al., 2016). According to South Egypt Cancer Institute statistical records, the incidence of breast cancer in 2014 were about 490 patients (483 females and 7 males), (Statistical Records of South Egypt Cancer Institute, 2014).

Many women will have impairment in shoulder movement that can significantly affect their daily function and quality of life. Restriction of shoulder movement is one of the complications following modified radical mastectomy and axillary lymph node dissection; it may occur as a result of nerve and tissue lesions. To reduce the impairment of strength and mobility of the shoulder, shoulder exercises are commonly prescribed (Bahgat, et al., 2016).

Early physiotherapy especially shoulder exercise is a common treatment to avoid shoulder dysfunction and restricted shoulder mobility. Physical therapist can suggest and perform post mastectomy exercises that help to regain movement and strength in arm and shoulder, reduce stiffness and improve quality of life (Brito, et al., 2012 \& Galantino \& Stout, 2013).

Nurses are the largest group of health professionals who have direct contact with the patients, they play an important role in improving shoulder functions and restoring the full range of motion of shoulder and arm after modified radical mastectomy by giving certain directions and instructions regarding postoperative exercises and protective care measures to prevent shoulder dysfunction (Bahgat, et al., 2016). The nursing management of breast cancer patient includes assessing the patient's needs, making appropriate nursing diagnosis and 
initiate plans for care, helping her to cope with emotions, providing information and psychological support (Sullivan \& Mansour, 2015 \& Darweesh, et al., 2016).

\section{The Aim of the studys}

To identify the effect of applying shoulder exercises on shoulder function after modified radical mastectomy.

\section{Research hypotheses}

The following research hypotheses were formulated to fulfill the aim of the study

- Shoulder function in females in the study group will improve than that in females in the control group.

- Shoulder range of motion in females in the study group will improve than that in females in the control group.

\section{Significance of the study}

The researcher observed that there is an increase in the incidence of breast cancer in South Egypt Cancer Institute at Assiut University, about 490 patients (2014) and modified radical mastectomy is a common surgical procedure in breast cancer. After surgery, the most common postoperative complications are shoulder dysfunction and restricted shoulder mobility. To reduce or prevent these complications, shoulder exercises are usually prescribed.

Operational Definitions

Modified radical mastectomy (MRM)

Modified radical mastectomy is a removal of the entire breast in addition to axillary lymph nodes dissection.

\section{Shoulder exercises for modified radical} mastectomy

Shoulder exercises are physical activities that are done by women who had modified radical mastectomy to improve their shoulder function. These exercises include wall hand climbing, rope turning and rod lifting.

\section{Patients \& Method \\ Research design:}

A quasi-experimental research design was used in this study.

\section{Study variables}

The independent variable is shoulder exercises while the dependent variable is shoulder function and shoulder range of motion.

\section{Setting}

The study was conducted in the surgical oncology department and surgical outpatient clinic at South Egypt Cancer Institute - Assiut University.

\section{Patients}

A purposive sample of (80) adult female patients with breast cancer scheduled for modified radical mastectomy with mean ages $(45.5 \pm 11.7)$ for study group \& (44.8 \pm 10.8$)$ for control group. Patients were divided into two equal groups; (40) for each, the study group performed postmastectomy shoulder exercises and the control group received routine care. To ensure the randomization, the odd numbers were given to the group that performed post mastectomy shoulder exercises while the even numbers were given to the group that received routine care. They were selected according to the following criteria: conscious, in the preoperative period and accepted to participate in the study.

\section{Exclusion criteria included}

Patients with severe deformity, any trauma or diseases affecting muscles and joints such as rheumatoid arthritis, skin grafting on or around the shoulder, previous history of chronic illness such as diabetes, osteoporosis, renal failure, heart disease, pulmonary diseases, neurological dysfunction and patients undergoing neck surgery were excluded from the study subjects.

\section{Tools of data collection}

Three tools were used for data collection;

Tool (I): Structured Interview Questionnaire

It was developed by the researcher after extensive review of the relevant literature and it was used to obtain baseline data of the patients, it consisted of two parts:

Part I: Socio-demographic data: such as the patient's name, age, marital status, level of education, occupation and residence area.

Part II: Clinical data: such as diagnosis, date of admission, date of discharge, patient and family medical history, risk factors, etc.

Tool (II) - Shoulder Range of Motion Assessment Questionnaire:

It was adopted from McRae, (2004) and it was used to assess patients' shoulder motion through measuring shoulder range of motion in degrees with the universal manual goniometer. Elevation through forward flexion; normal range: 170- 180 degree, extension; normal range: 50 - 60 degree, abduction; normal range: 170-180 degree, internal rotation in abduction; normal range: 50 - 70 degree, external rotation in abduction; normal range: 90 - 100 degree and adduction; normal range: 50 - 75 degree. Postoperative shoulder motion was assessed as impaired if the range of motion was reduced more than 10 degrees and as full if the range of motion was reduced 10 degrees or less compared to the preoperative range of motion (Schultz, et al., 1997). Impaired range of motion was given a score of (1) and full range of motion was given a score of (2).

Tool (III) - Shoulder Functional Ability Assessment Questionnaire:

It was adopted from American shoulder and elbow surgeons' shoulder evaluation form McRae, (2004) and it was used to assess functional abilities of the affected shoulder. It was translated into Arabic and it includes 13 questions regarding the ability to perform specific activities as using the hand 
overhead, dressing, combing the hair, etc. Each activity was evaluated on a scale of $0-4$ and the results were summed $(0=$ unable, $1=$ only with assistance, $2=$ with difficulty, $3=$ mild compromise, 4 = normal).

\section{Teaching material (booklet)}

It was designed to give patients written instructions about shoulder exercises including wall hand climbing, rope turning and rod lifting, how to change the dressing and clean the skin around drain tubing and signs of wound infection. It was constructed and filled by the researcher after passing through an extensive and relevant literature review in the form of booklet using simple Arabic language and different illustrated pictures to facilitate understanding of its contents.

\section{Administrative approval}

An official permission was obtained from the head of South Egypt Cancer Institute at Assiut University.

- The first tool (structured interview questionnaire) was developed by the researcher after extensive review of the relevant literature. The tool (I) (structured interview questionnaire) was tested for content validity by five experts of academic medical and nursing staff at Assiut University. Modifications were done accordingly, and then the tool was designed in their final format and tested for reliability using internal consistency for the tool measured using Cronbach alpha test, the tools were proved to be reliable (0.87) (Acceptable alpha $\geq 0.7$ ).

\section{Ethical considerations}

- Research proposal were approved from Ethical Committee in the Faculty of Nursing.

- An oral permission for voluntary participation was obtained from patients and the nature and purpose of the study were explained.

- There is no risk for the study patient during application of the research.

- The researcher initially introduced herself to all patients and they were assured that the collected data would be absolutely confidential.

- Patients were informed that participation is voluntary and that they could withdraw at any time of the study. Confidentiality of the patient's data was ascertained.

- Confidentiality and anonymity were assured.

- Patients' names were coded for data entry so that their names could not be identified.

\section{Pilot study}

Pilot study was conducted on $10 \%$ of the sample ( 8 patients) in the selected setting to evaluate the applicability \& clarity of the tools. According to this pilot study, the required modifications were made. These patients were excluded from the study sample.

\section{Data collection}

Data were collected from February 2016 to October 2016. The data collection was done through the following phases:

\section{Preparatory phase (Assessment phase)}

The researcher interviewed the patients with breast cancer who were scheduled for modified radical mastectomy preoperatively at the surgical oncology department to explain purpose and nature of the study and get their oral consent to participate in the study. Categorization of the patients into two groups (study and control) (40 patients for each) was done.

The researcher collected baseline data from both groups (study and control) using tool (I) part (I, II), measure shoulder range of motion exercises with universal manual goniometer using tool (II). Elevation through forward flexion, ask the patient to swing the arm forward and lift it above the head. View the patient from the side. Backward extension, ask the patient to swing the arm directly backwards, view and measure from the side. Abduction, measure the range of abduction, in normal shoulder the arm can touch the ear with only slight tilting of the head. Internal rotation in abduction, abduct the shoulder to 90 degree and flex the elbow to the right angle. Ask the patient to lower the forearm from the horizontal plane. External rotation in abduction from the same starting position with the forearm parallel to the ground, ask the patient to raise the hand, keeping the shoulder in (90) degree abduction. Adduction in extension, place one hand on the shoulder and swing the arm, flex at the elbow across the chest. In addition, functional abilities of the affected shoulder were measured by asking the patients to perform specific activities using tool (III) for both groups.

\section{Implementation phase}

Patients in the study group were interviewed individually by the researcher in the preoperative period at the surgical oncology department for twice and received two sessions for about 40 minutes for each. The first session started by explaining the purpose and nature of the study and the objectives of the session then includes oral and written instructions about post-mastectomy shoulder exercises (wall hand climbing, rope turning and rod lifting). The second session usually started by a summary of what had been taught during the previous session and the objectives of the new session then includes oral and written instructions about how to change the dressing and clean the skin around drain tubing and signs of wound infection. After each session, there was 10 minutes for discussion and giving feedback. Reinforcement of teaching was performed according to patient's needs to ensure their understanding. Each patient in the study group obtained a copy of the teaching booklet. 
Patients in the study group were encouraged to use the affected arm in activities of daily living and were encouraged to perform postmastectomy shoulder exercises, demonstration and redemonstration several times until performance without error was done.

The study group: this group performed postmastectomy shoulder exercises on the second day postoperatively, two times daily for 20 minutes each time and continued these exercises at home after discharge for one month.

The control group: this group received routine hospital care.

-After discharge, the researcher contacted each patient in the study group by telephone to be sure that she was following the given instructions and to encourage her to follow them and practice the shoulder exercises continuously on the specified times.

\section{Evaluation phase}

1- Shoulder range of motion and functional abilities of the affected shoulder were evaluated by the researcher in the surgical outpatient clinic one week after starting the exercises for the study and the control groups and then one month after patients discharge from hospital for both groups using tool (II, III) respectively.

Statistical Design

Data entry and statistical analysis were done using IBM SPSS computer program "version 20.0" software. The data were tested for normality using the Anderson-Darling test and for homogeneity variances prior to further statistical analysis. Categorical variables were described by number and percent (N, \%). Continuous variables described by mean and standard deviation (Mean, $\mathrm{SD})$. Chi-square test used to compare between categorical variables. T-test used to compare between continuous variables, statistical significance was considered at p-value $<0.05$.

\section{Difficulties of the study}

- Level of literacy in patient population limits their ability to access or benefit from some parts in the educational booklet because of lack in their reading ability. To solve this problem, each patient in the study group was given a copy of all available mass media as posters, pictures and brochures.

- Some patients did not attend follow up until the researcher reminded them about follow up. These patients were excluded from the study sample. To overcome that, we replace the excluded patients by other patients to maintain suitable number of the study sample (80 patients). 


\section{Results}

Table (1): Frequency distribution of Socio-demographic characteristics of both groups $(n=40)$.

\begin{tabular}{|c|c|c|c|c|c|}
\hline \multirow{2}{*}{ Socio- demographic characteristics } & \multicolumn{2}{|c|}{ Study $(n=40)$} & \multicolumn{2}{|c|}{ Control $(n=40)$} & \multirow{2}{*}{ P. value } \\
\hline & n. & $\%$ & n. & $\%$ & \\
\hline \multicolumn{6}{|l|}{ Age } \\
\hline $30->40$ years & 12 & 30.0 & 14 & 35.0 & \multirow{2}{*}{$0.633^{\mathrm{ns}}$} \\
\hline $40-60$ years & 28 & 70.0 & 26 & 65.0 & \\
\hline Mean \pm SD & \multicolumn{2}{|c|}{$45.5 \pm 11.7$} & \multicolumn{2}{|c|}{$44.8 \pm 10.8$} & $\mathbf{0 . 7 8 2}{ }^{\mathrm{ns}}$ \\
\hline \multicolumn{6}{|l|}{ Marital status: } \\
\hline Married & 28 & 70.0 & 30 & 75.0 & \multirow{3}{*}{$0.837^{\mathrm{ns}}$} \\
\hline Divorced & 4 & 10.0 & 4 & 10.0 & \\
\hline Widow & 8 & 20.0 & 6 & 15.0 & \\
\hline \multicolumn{6}{|l|}{ Level of education } \\
\hline Illiterate & 22 & 55.0 & 20 & 50.0 & \multirow{5}{*}{$0.788^{\text {ns }}$} \\
\hline Reads and writes & 6 & 15.0 & 6 & 15.0 & \\
\hline Primary education & 8 & 20.0 & 6 & 15.0 & \\
\hline Secondary education & 2 & 5.0 & 4 & 10.0 & \\
\hline University education & 2 & 5.0 & 4 & 10.0 & \\
\hline \multicolumn{6}{|l|}{ Occupation: } \\
\hline Housewife & 34 & 85.0 & 32 & 80.0 & \multirow{2}{*}{$0.556^{\mathrm{ns}}$} \\
\hline Employee & 6 & 15.0 & 8 & 20.0 & \\
\hline \multicolumn{6}{|l|}{ Residence } \\
\hline Village & 30 & 75.0 & 26 & 65.0 & \multirow{2}{*}{$0.329^{\mathrm{ns}}$} \\
\hline City & 10 & 25.0 & 14 & 35.0 & \\
\hline \multicolumn{6}{|l|}{ Do you have children } \\
\hline Yes & 40 & 100.0 & 40 & 100.0 & - \\
\hline
\end{tabular}

Table (2): Comparison between the study and the control groups as regards shoulder range of motion $(n=40)$.

\begin{tabular}{|c|c|c|c|c|c|c|c|c|c|}
\hline \multirow{3}{*}{$\begin{array}{l}\text { Shoulde } \\
\text { r range } \\
\text { of motion }\end{array}$} & \multicolumn{3}{|c|}{ Before Operation } & \multicolumn{3}{|c|}{ One week After } & \multicolumn{3}{|c|}{ One month After } \\
\hline & \multirow{2}{*}{$\begin{array}{c}\text { Study } \\
\text { Mean } \pm \text { SD }\end{array}$} & \multirow{2}{*}{$\begin{array}{c}\text { Control } \\
\text { Mean } \pm \text { SD }\end{array}$} & \multirow{2}{*}{$\begin{array}{c}P . \\
\text { value }\end{array}$} & \multirow{2}{*}{$\begin{array}{c}\text { Study } \\
\text { Mean } \pm \text { SD }\end{array}$} & \multirow{2}{*}{$\begin{array}{c}\text { Control } \\
\text { Mean } \pm \text { SD }\end{array}$} & \multirow{2}{*}{ P. value } & \multirow{2}{*}{$\begin{array}{c}\text { Study } \\
\text { Mean } \pm \text { SD }\end{array}$} & \multirow{2}{*}{$\begin{array}{c}\text { Control } \\
\text { Mean } \pm \text { SD }\end{array}$} & \multirow{2}{*}{ P. value } \\
\hline & & & & & & & & & \\
\hline $\begin{array}{l}\text { Elevation } \\
\text { through } \\
\text { forward } \\
\text { flexion }\end{array}$ & $172.7 \pm 1.4$ & $172.6 \pm 1.8$ & 0.778 & $161.4 \pm 4.0$ & $157.4 \pm 4.6$ & $<0.000 * *$ & $163.8 \pm 3.8$ & $159.8 \pm 4.7$ & $<0.001 * *$ \\
\hline Extension & $51.9 \pm 1.5$ & $51.9 \pm 1.2$ & 0.871 & $40.6 \pm 3.9$ & $37.3 \pm 4.1$ & $<0.000^{* *}$ & $43.9 \pm 3.5$ & $39.7 \pm 4.1$ & $<0.001 * *$ \\
\hline Abduction & $171.3 \pm 1.4$ & $171.7 \pm 1.1$ & 0.192 & $159.8 \pm 4.2$ & $156.6 \pm 3.6$ & $<0.000^{* * *}$ & $163.1 \pm 3.7$ & $158.9 \pm 3.8$ & $<0.001^{* * *}$ \\
\hline Adduction & $52.7 \pm 1.7$ & $53.6 \pm 1.5$ & $0.012 *$ & $41.8 \pm 3.04$ & $39.0 \pm 4.5$ & $0.002 * *$ & $44.7 \pm 3.0$ & $41.4 \pm 4.7$ & $<0.001 * *$ \\
\hline $\begin{array}{l}\text { Internal } \\
\text { rotation in } \\
\text { abduction }\end{array}$ & $51.5 \pm 1.2$ & $51.7 \pm 1.2$ & 0.444 & $40.3 \pm 3.6$ & $37.1 \pm 4.3$ & $0.001 * *$ & $43.3 \pm 3.5$ & $39.6 \pm 4.3$ & $<0.001 * *$ \\
\hline $\begin{array}{l}\text { External } \\
\text { rotation in } \\
\text { abduction }\end{array}$ & $91.9 \pm 1.5$ & $92.3 \pm 1.5$ & 0.195 & $80.3 \pm 3.3$ & $77.1 \pm 5.0$ & $0.001 * *$ & $83.5 \pm 2.7$ & $79.9 \pm 5.1$ & $<0.001 * *$ \\
\hline
\end{tabular}

${ }^{n s}=$ Non significant difference $(p>0.05)$

* Statistically significant difference $(p<0.05)$

**Highly statistically significant difference $(p<0.01)$ 
Table (3): Comparison between the study and the control groups regarding shoulder function.

\begin{tabular}{|c|c|c|c|c|c|c|c|c|c|}
\hline \multirow{2}{*}{ Shoulder function } & \multicolumn{3}{|c|}{$\begin{array}{c}\text { Before Operation } \\
\text { Mean } \pm \text { SD }\end{array}$} & \multicolumn{3}{|c|}{$\begin{array}{c}\text { One week After } \\
\text { Mean } \pm \text { SD }\end{array}$} & \multicolumn{3}{|c|}{$\begin{array}{c}\text { One month } \\
\text { Mean } \pm \text { SD }\end{array}$} \\
\hline & Study & Control & $\begin{array}{c}P . \\
\text { value }\end{array}$ & Study & Control & P. value & Study & Control & P. value \\
\hline $\begin{array}{l}\text { Putting the hand } \\
\text { in a back pocket }\end{array}$ & $4 \pm 0$ & $4 \pm 0$ & 1.000 & $2.05 \pm 0.88$ & $1.45 \pm 0.93$ & $0.004 * *$ & $3.55 \pm 0.81$ & $2.65 \pm 0.98$ & $0.001 * *$ \\
\hline $\begin{array}{l}\text { Washing the } \\
\text { opposite axilla }\end{array}$ & $4 \pm 0$ & $4 \pm 0$ & 1.000 & $2.15 \pm 0.92$ & $1.35 \pm 0.92$ & $0.000 * *$ & $3.55 \pm 0.81$ & $2.7 \pm 0.91$ & $0.001 * *$ \\
\hline Combing the hair & $4 \pm 0$ & $4 \pm 0$ & 1.000 & $1.8 \pm 0.94$ & $0.9 \pm 0.9$ & $0.000^{* *}$ & $3.35 \pm 0.8$ & $2.5 \pm 0.82$ & $0.001 * *$ \\
\hline $\begin{array}{l}\text { Carrying } 4.5 \mathrm{~kg} \\
\text { at the side }\end{array}$ & $4 \pm 0$ & $4 \pm 0$ & 1.000 & $1.35 \pm 0.92$ & $0.55 \pm 0.88$ & $0.000 * *$ & $2.6 \pm 0.81$ & $1.6 \pm 0.74$ & $0.001 * *$ \\
\hline $\begin{array}{l}\text { Sleeping on the } \\
\text { affected side }\end{array}$ & $4 \pm 0$ & $4 \pm 0$ & 1.000 & $2.05 \pm 0.81$ & $1.45 \pm 0.99$ & $0.004 * *$ & $3.65 \pm 0.66$ & $3.1 \pm 0.84$ & $0.002 * *$ \\
\hline $\begin{array}{l}\text { Using the hand } \\
\text { over head }\end{array}$ & $4 \pm 0$ & $4 \pm 0$ & 1.000 & $2.45 \pm 0.81$ & $1.5 \pm 0.88$ & $0.000 * *$ & $3.6 \pm 0.81$ & $2.85 \pm 0.98$ & $0.001 * *$ \\
\hline Lifting & $4 \pm 0$ & $4 \pm 0$ & 1.000 & $2.05 \pm 0.93$ & $0.95 \pm 0.75$ & $0.000^{* *}$ & $3.1 \pm 0.71$ & $2.1 \pm 0.84$ & $0.001 * *$ \\
\hline Perineal care & $4 \pm 0$ & $4 \pm 0$ & 1.000 & $2.55 \pm 0.81$ & $1.45 \pm 0.81$ & $0.000^{* *}$ & $3.65 \pm 0.66$ & $2.85 \pm 0.98$ & $0.001 * *$ \\
\hline $\begin{array}{l}\text { Eating with } \\
\text { utensil }\end{array}$ & $4 \pm 0$ & $4 \pm 0$ & 1.000 & $2.75 \pm 0.63$ & $2.05 \pm 0.68$ & $0.000 * *$ & $3.75 \pm 0.44$ & $3.4 \pm 0.5$ & $0.001 * *$ \\
\hline $\begin{array}{l}\text { Using the arm at } \\
\text { shoulder level }\end{array}$ & $4 \pm 0$ & $4 \pm 0$ & 1.000 & $2 \pm 0.85$ & $1.35 \pm 0.66$ & $0.000 * *$ & $3.15 \pm 0.74$ & $2.5 \pm 0.68$ & $0.001 * *$ \\
\hline Dressing & $4 \pm 0$ & $4 \pm 0$ & 1.000 & $2.5 \pm 0.88$ & $1.5 \pm 0.88$ & $0.000^{* *}$ & $3.65 \pm 0.74$ & $2.8 \pm 0.94$ & $0.001 * *$ \\
\hline Pulling & $4 \pm 0$ & $4 \pm 0$ & 1.000 & $2.15 \pm 0.92$ & $1.25 \pm 1.01$ & $0.000^{* *}$ & $3.45 \pm 0.81$ & $2.8 \pm 0.88$ & $0.001 * *$ \\
\hline Throwing & $4 \pm 0$ & $4 \pm 0$ & 1.000 & $1.45 \pm 0.81$ & $0.7 \pm 0.85$ & $0.000 * *$ & $2.7 \pm 0.91$ & $2.05 \pm 0.81$ & $0.001 * *$ \\
\hline $\begin{array}{l}\text { Total mean score } \\
\text { of shoulder } \\
\text { function }\end{array}$ & $52 \pm 0$ & $52 \pm 0$ & 1.000 & $27.3 \pm 10$ & $16.5 \pm 9.9$ & $<0.001 * *$ & $43.7 \pm 8.9$ & $33.9 \pm 10.2$ & $<0.001 * *$ \\
\hline
\end{tabular}

${ }^{n s}=$ Non significant difference $(p>0.05)$

* Statistically significant difference $(p<0.05)$

**Highly statistically significant difference $(p<0.01)$

Table (4): Relation between the outcome of the shoulder function and demographic characteristics (age and residence) of the study group $(n=40)$.

\begin{tabular}{|c|c|c|c|c|c|c|c|c|c|c|}
\hline \multirow{3}{*}{ Shoulder function } & \multicolumn{4}{|c|}{ Age } & \multirow{3}{*}{ P. value } & \multicolumn{4}{|c|}{ Residence } & \multirow{3}{*}{ P. value } \\
\hline & \multicolumn{2}{|c|}{$30-<40$ years } & \multicolumn{2}{|c|}{ 40- 60 years } & & \multicolumn{2}{|c|}{ Village } & \multicolumn{2}{|c|}{ City } & \\
\hline & n. & $\%$ & n. & $\%$ & & n. & $\%$ & n. & $\%$ & \\
\hline \multicolumn{11}{|l|}{ Before operation } \\
\hline Normal & 12 & 100.0 & 28 & 100.0 & - & 30 & 100.0 & 10 & 100.0 & - \\
\hline \multicolumn{11}{|l|}{ After one week } \\
\hline Only with assistance & 2 & 16.7 & 12 & 42.9 & \multirow[b]{2}{*}{$0.112^{\text {ns }}$} & 10 & 33.3 & 4 & 40.0 & \multirow[b]{2}{*}{$0.702^{\mathrm{ns}}$} \\
\hline Mild compromise & 10 & 83.3 & 16 & 57.1 & & 20 & 66.7 & 6 & 60.0 & \\
\hline \multicolumn{11}{|l|}{ After one month } \\
\hline With difficulty & 0 & 0.0 & 8 & 28.6 & \multirow{2}{*}{$0.038^{*}$} & 6 & 20.0 & 2 & 20.0 & \multirow{2}{*}{$1.000^{\mathrm{ns}}$} \\
\hline Normal & 12 & 100.0 & 20 & 71.4 & & 24 & 80.0 & 8 & 80.0 & \\
\hline
\end{tabular}


Table (5): Relation between outcome of shoulder function and demographic characteristics (level of education and occupation) of the study group $(n=40)$.

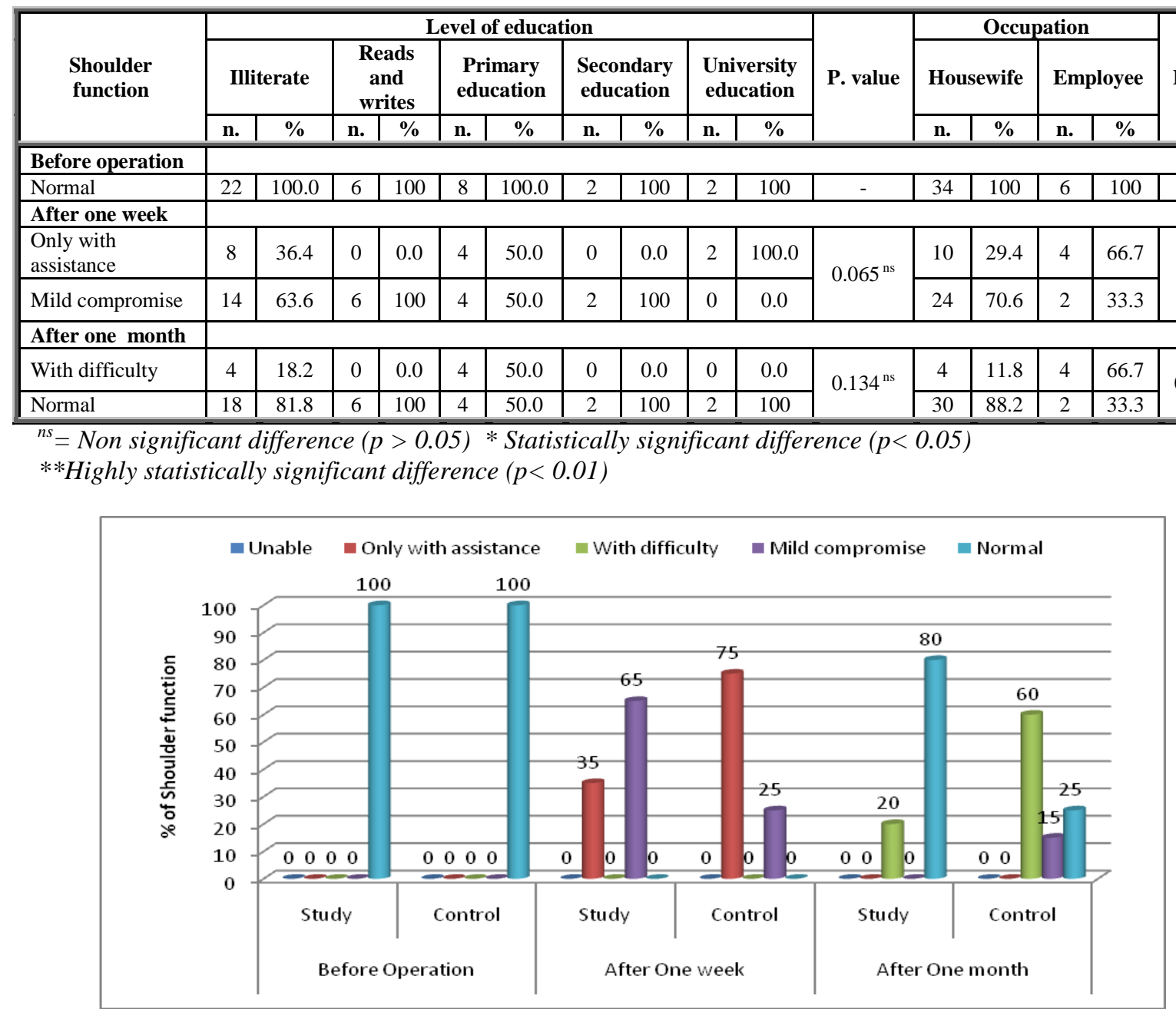

Figure (1): Frequency distribution of the outcome of shoulder function of both groups.

Table (1): Showed that more than half of women in both groups (70\% and 65\%) respectively, their ages ranged between (40 to 60) years with mean ages $(45.5 \pm 11.7)$ for the study group \& $(44.8 \pm 10.8)$ for the control group. Most of the women in the study and the control groups were married and illiterate $(70 \%, 75 \%$ and $55 \%, 50 \%)$ respectively. Regarding occupation, the majority of the women in both groups were housewives (80\% and 85\%) respectively. More than half of the women in the study and the control groups (75\% and 65\%) respectively were living in rural areas. As regard to having children, all of the women in both groups had children. Finally, the table illustrated that there was no statistical difference between the study and the control groups regarding sociodemographic characteristics $(\mathrm{p}>0.05)$.

Table (2): Revealed that there was a high significant improvement in the study group compared to the control group regarding shoulder range of motion in (elevation through forward flexion, extension, abduction, adduction, internal rotation in abduction and external rotation in abduction) one week and one month after starting the exercises $(\mathrm{p}<0.01)$.

Table (3): Clarifies that there was a highly significant improvement in the study group compared to the control group regarding shoulder function one week and one month after starting the exercises $(\mathrm{p}<0.01)$.

Table (4): Illustrated that there was a significant relation between the outcome of the shoulder function and ages of the study group after one month $(\mathrm{p}<0.05)$. In addition, the table showed that there was no significant relation between the 
outcome of the shoulder function and residence of the study group $(\mathrm{p}>0.05)$.

Table (5): Clarified that there was no significant relation between outcome of shoulder function and level of education of the study group ( $p>0.05)$. In addition, the table illustrated that there was significant relation between outcome of shoulder function after one month and occupation of the study group $(\mathrm{p}<0.05)$.

Figure (1): Revealed that all women in the study and the control groups had normal shoulder function before operation. More than half of the study group $(65 \%)$ had mild compromised shoulder function while most of the women in the control group (75\%) need assistance in performing the shoulder function one week after starting exercises. Most of the study group $(80 \%)$ had normal shoulder function while $(60 \%)$ of the control group had difficulty in performing the shoulder function one month after starting exercise. Finally, the table showed that there was a highly significant improvement in the study group compared to the control group regarding the shoulder function one week and one month after starting exercises $(\mathrm{p}<0.01)$.

\section{Discussion}

Based on the results of the present study, more than half of the women in both groups, their ages ranged between (40to 60) years with mean ages $(45.5 \pm 11.7)$ for the study group \& $(44.8 \pm 10.8)$ for the control group. This means that both the immune response and the hormonal changes altering with aging are associated with breast cancer. This finding was in the same line with Ibrahim, et al., (2012), who concluded that, more than half of the studied women were ranging between 40 to less than 60 years old. Also, Azeaz, et al., (2013), mentioned that the mean age of the women in both groups was $45.25 \pm 5.86$ for the study group and $46.06 \pm 6.19$ for the control group.

Regarding marital status, most of the women of the study and the control groups were married. This result was in agreement with Bahgat, et al., (2016), who mentioned that the majority of the women in studied groups were married.

In relation to the educational level, most of the women in both groups were illiterate and more than half of the women in both groups were living in rural areas. This is due to the fact that illiteracy rate is higher among women in Egypt accounting (69\%) of the total number of illiterate people in Egypt. This result was in accordance with Ibrahim, et al., (2012), who reported that more than one third of the study group and one-half of the control group were illiterate. This finding contradicted with Beiki, et al., (2012), who revealed that women with the highest educational level had increased incidence of breast cancer when compared to the women with lower education.

Regarding occupation, the majority of the women in both groups were housewives. It could be due to high rate of illiteracy among Egyptian women. This result was in agreement with Azeaz, et al., (2013), who reported that most of both groups were housewives. In addition, this study finding was in accordance with Sallam, et al., (2013), who presented that the majority of the studied women were housewives. Regarding residence area, more than half of the women of the study and the control groups were living in rural areas. This finding was in agreement with Bahgat, et al., (2016), who reported that about half of the study group and more than half of the control group were residence in rural areas.

Regarding shoulder range of motion and shoulder function, the present study revealed that there was a highly significant improvement in the study group compared to the control group one week and one month after exercises start $(\mathrm{p}<0.01)$. This means that the study group restored full shoulder range of motion and attained shoulder function more than the control group after applying shoulder exercises following surgery. This means that shoulder exercise that was taught had a positive effect in improving shoulder function and helping patients to return to their previous level of performance in work and daily life, if the patient practices them regularly.

This result was supported by Azeaz, et al., (2013), who reported that there was a significant improvement in shoulder function in the study group in the short term than the control group post program and after one month of implementation of the educational program (shoulder exercises). Moreover, Fung et al., (2011), mentioned that physiotherapy and rehabilitation program was proved to be efficient and safe in restoring the full range of motion of shoulder and arm and improving shoulder function without any complications. Also Keays, et al., (2016), showed that the greatest improvement in shoulder range of motion followed implementation of the intervention.

This result was also corresponding with Park, et al., (2006) \& Bahgat, et al., (2016), who revealed that the greatest improvement in internal rotation, external rotation and flexion of shoulder occurred in the study group when compared to the control group. In addition, Keays, et al., (2016), revealed that a significant improvement in shoulder range of motion in abduction, flexion and external rotation followed implementation of the educational 
program in the study group compared to the control group.

This finding is in consistent with Chan, et al., (2010), who revealed that there was a significant improvement in shoulder mobility and shoulder function in the study group. Moreover, the improvement in measurements of abduction and flexion movements of the shoulder was statistically significant better in the study group.

Moreover, Sallam, et al., (2013), revealed that shoulder exercises improved shoulder range of motion in internal rotation and extension in both studied groups but there was no significant difference between early and delayed shoulder exercises. Moreover, Lotze, et al., (2011), reported that sufficient functional range of motion was attained in all patients without major complications after applying postmastectomy shoulder exercises, but there were no significant differences between the patients receiving early or delayed exercises postoperatively at any time interval (1, 3, 6 months). This finding was matched with McNeely, et al., (2010), who found that upper limb exercise (e.g. shoulder range of motion) is useful in recovering and improving upper limb movement and improves shoulder range of motion after surgery for breast cancer patients. Starting exercise early after surgery (first day to third day) may result in the greatest improvement in shoulder movement in the short term and it is useful to regain shoulder movement and its use for daily activities such as reaching overhead.

These results were consistent with Loh \& Musa, (2015), who reported that exercises rehabilitation showed a significant improvement in shoulder movement with early exercises more than the delayed ones. Moreover, Galantino \& Stout, (2013), reported that early physiotherapy especially postmastectomy shoulder exercises is a common treatment to prevent shoulder dysfunction and restricted shoulder mobility. Nurse or physical therapist can suggest and perform shoulder exercises that help to improve and regain movement and strength in arm and shoulder without any complications and improve quality of life.

Also, Gautam, et al., (2011), Azeaz, et al., (2013) \& Mahdy, (2014), mentioned that full range of motion returns after proper postmastectomy shoulder exercises. Both arms can be extended fully and equally high over the head. The woman benefits from having something active to do to help herself during the hard time of adjustment after modified radical mastectomy. Many activities of daily living provide good exercise, such as hanging clothes, reaching high shelves, and gardening.
This finding was in the same line with Shaaban, (2013), who reported that therapeutic exercise has many benefits for all the patients after operation. Exercises are important to prevent contracture of the joints, shortening of the muscles and to improve lymph and blood circulation after mastectomy. Moreover, self-care activities, such as combing the hair, washing the face and brushing the teeth are physically and emotionally therapeutic because they aid in returning and restoring the shoulder function and the sense of normalcy for the patients after mastectomy (Hinkle \& Cheever, 2014).

Lauridsen, et al., (2016), was in the same line with the present study revealing that physiotherapy significantly improves shoulder function for breast cancer patients treated surgically. Moreover, Chung, et al., (2013), mentioned that physical therapy is useful for shoulder range of motion when performed early after surgery. Any type of exercise could improve shoulder mobility, shoulder function, and shoulder range of motion, in short period.

This result is in line with Fung, et al., (2011), who concluded that physiotherapy program was proved to be useful in recovering and improving shoulder function with minimum complications. Also, Brito, et al., (2012) \& Gautam, et al., (2011), reported that to prevent shoulder dysfunction, reduce the impairment of strength and mobility of shoulder and to avoid lymphoedema after mastectomy, postmastectomy shoulder exercises are usually prescribed.

The results of the current study revealed that there was a significant relation between the outcome of the shoulder function and ages of the study group after one month. This means that the younger patients had more improvement in shoulder function when compared to the group of the older patients. Also, incidence of shoulder dysfunction and restricted shoulder mobility increases with aging due to altered immune response with aging, decreased ability to perform specific activities as combing the hair and using the hand overhead, and decreased ability to do postmastectomy shoulder exercises regularly.

This finding was in agreement with Azeaz, et al., (2013), who revealed that there was a significant relation between patient's age and Shoulder Pain and Disability Index (SPADI) scores post program and after one month of implementation of intervention. This means that the group of younger patients had less SPADI score than the older ones. Finally, it can be concluded that applying shoulder exercises for patients undergoing modified radical mastectomy is considered a corner stone in improving shoulder function and restoring the full range of motion of shoulder and arm. 


\section{Conclusion}

Based on the results of the present study, it can be concluded that

- There was a highly significant improvement in the study group compared to the control group regarding shoulder function and shoulder range of motion one week and one month after exercises start $(\mathrm{p}<0.01)$.

- Utilizing postmastectomy shoulder exercises significantly improves shoulder function, restores full range of motion of shoulder and arm, improves shoulder mobility, reduced shoulder dysfunction for patients undergoing modified radical mastectomy.

\section{Recommendations}

Increase level of awareness among patients undergoing modified radical mastectomy regarding shoulder exercises using all available mass media as posters and brochures. Start shoulder exercises early after surgery. Periodic training program for nurses regarding the importance of postmastectomy shoulder exercises. Further study is recommended to study effect of applying shoulder exercises on shoulder function on the long term and its effect on their quality of life.

\section{Reference}

1. American Cancer Society, (ACS) (2015): Breast cancer facts \& figures 2015 - 2016. Atlanta, GA: American Cancer Society, Pp. 144. Available at http://www.cancer.org/cancer/breastcancerfacta ndfigure/index.pdf. Accessed at 20/1/2017.

2. Azeaz, M., Taha, N., Hassan, A., \& Shaban, A., (2013): Effect of Educational Program Regarding Therapeutic Exercises on Women's Pain, Fatigue and Shoulder Function Undergoing Mastectomy. J Am Sci, Vol. (9), No. (3), Pp. 412-425.

3. Bahgat, Z., Alaa Elden, S., Atia, N., EL Shikh, E., and Elshemy, M., (2016): The Efficacy of Protocol of Care on Post Mastectomized Women Outcomes. IOSR Journal of Nursing and Health Science (IOSRJNHS), Vol. (5), No. (5), Pp. 49-64.

4. Beiki, O., Hall, P., Ekbom, A., \& Moradi, T., (2012): Breast cancer incidence and case fatality among 4.7 million women in relation to social and ethnic background: a populationbased cohort study. Breast Cancer Res, Vol. (14), Pp.5.

5. Brito, C., Lourencao, M., Saul, M., Bazan, M., Otsubo, P., \& Imamura, M., (2012):
Breast cancer: rehabilitation. Acta Fisiatr, Vol. (19), No. (2), Pp. 66-72.

6. Chan, D., Lui, L., \& So, W., (2010): Effectiveness of exercise programmes on shoulder mobility and lymphoedema after axillary lymph node dissection for breast cancer: systematic review. Journal of Advanced; Vol. (66), No. (9), Pp. 1902-1914.

7. Chung, C., Lee, S., Hwang, S., \& Park, E., (2013): Systematic review of exercise effects on health outcomes in women with breast cancer. Asian Nursing Research, Vol. (7), Pp. 149-159.

8. Darweesh, H., Abdel Hadi, M., Al Madani, R., \& Al Mahsen, Z., (2016): Reviving Nurses' Role as Health Educators; Breast Cancer in a Developing Country. Nursing Research and Practice, Vol. (01), No. (01), Pp. 001-005.

9. Faisal, M., Abu-Elela, S., Mostafa, W., \& Antar, O., (2016): Efficacy of axillary exclusion on seroma formation after modified radical mastectomy. World Journal of Surgical Oncology, Vol. (14), No. (39), Pp. 1-5.

10. Fung, Y., Choi, W., Lo, T., Au, T., Choi, W., \& Tam, C., (2011): Efficacy of modified 3 phases exercise program for patient following breast cancer surgery at Tseung Kwan $\mathrm{O}$ Hospital. Meeting Abstracts.

11. Galantino, M., \& Stout, N., (2013): Exercise interventions for upper limb dysfunction due to breast cancer treatment. Physical Therapy, Vol. (93), No. (10), Pp. 1291-1297.

12. Gautam, A., Maiya, A. \& Vidyasagar, M., (2011): Effect of home-based exercise program on lymphedema and quality of life in female postmastectomy patients: Pre-post intervention study. Journal of Rehabilitation Research \& Development. Vol. (48), No. (10), Pp. 12611268.

13. Hinkle, J., \& Cheever, K., (2014): Brunner \& Suddarth's Textbook of Medical-Surgical Nursing, Assessment and Management of Patients with breast disorders, $13^{\text {th }}$ ed., chapter 58, Philadelphia, Lippincott Williams \& Wilkins, Pp.1680- 1710.

14. Ibrahim, R., Mohasib, S., Fayed, M., \& Ramadan, S., (2012): Assessment the Effect of Breast Cancer on Women's Quality of Life. Unpublished Master Thesis in Maternal and Newborn health nursing, Faculty of nursing. Banha University.

15. Keays, K., Harris, S., Lucyshyn, J., \& MacIntyre, D., (2016): Effects of Pilates Exercises on Shoulder Range of Motion, Pain, Mood, and Upper-Extremity Function in 
Women Living With Breast Cancer: A Pilot Study. Physical Therapy, Vol. (88), No. (4), Pp. 494-510.

16. Lauridsen, M., Christiansen, P., \& Hessov, I., (2016): The effect of physiotherapy on shoulder function in patients surgically treated for breast cancer: A randomized study. Acta Oncologica, Vol. (44), Pp. 449-457.

17. Loh, S., \& Musa, A., (2015): Methods to improve rehabilitation of patients following breast cancer surgery: a review of systematic reviews. Breast Cancer: Targets and Therapy, Pp. 781-98.

18. Lotze, M., Michael, T., Mary, A. \& Lynnh, H., (2011): Early versus delayed motion following axillary dissection. J. B. Lippincott Company, Vol. (193), No. (3), Pp. 288-295.

19. Mahdy, M., (2014): Effect of early post mastectomy exercises program for women on their upper limb function, Unpublished Doctorate thesis, Faculty of Nursing, Banha University.

20. McGuire, A., Brown, J., Malone, C., McLaughlin, R., \& Kerin, M., (2015): "Effects of age on the detection and management of breast cancer". Cancers, Vol. (7), No. (2), Pp. 908-29.

21. McNeely, M., Campbell, K., Courneya, K., Dabbs K., Mackey, J., Ospina, M. and Rowe, B., (2010): Exercise interventions for upper limb dysfunction due to breast cancer surgery. The Cochrane Library. Vol. (2), Pp.1-6.

22. McRae, R., (2004): Clinical orthopedic examination, $5^{\text {th }}$ ed., London, Churchill Livingstone Company, P. 57.

23. Park, H., Park, G., \& Cho, K., (2006): The effects of a rehabilitation program on physical health, physiological indicator and quality of life in breast cancer mastectomy patients' .Korean Society of Nursing Science, Vol. (36), Pp. 310-320.

24. Saini, K., Taylor, C., Ramirez, A., Palmieri, C., Gunnarsson, U., Schmoll, H., Dolci, S., Ghenne, C., Filho, O., Skrzypski, M., Paesmans, M., Ameye, L., Gebhart, M., \& de Azambuja, E., (2011): "Role of the multidisciplinary team in breast cancer management: results from a large international survey involving 39 countries". Annals of Oncology, Vol. (23), No.(4), Pp. 853-9.

25. Sallam, S., Mohsen, M., El Kased, A., \& El Badawy, A., (2013): The Effect of Early Versus Delayed Shoulder Exercises on Seroma Formation and Shoulder Function after Modified Radical Mastectomy: Thesis for Doctoral Degree in Nursing Science, Medical
Surgical Nursing, Faculty of Nursing, Menoufyia University, Egypt.

26. Schultz, I., Barholm, M., \& Grondal, S., (1997): Delayed shoulder exercises in reducing seroma frequency after modified radical mastectomy: a prospective randomized study. Ann Surg Oncol., Vol. (4), No. (4), Pp. 293-7.

27. Shaaban, A., (2013): Effect of Educational Program Regarding Therapeutic Exercises for Women Undergoing Mastectomy. Unpublished Doctorate Thesis, Faculty of Nursing, Mansoura University.

28. Statistical Records of South Egypt Cancer Institute, (2014): The incidence of breast cancer, Assiut University; Pp.1-20.

29. Sullivan, D., \& Mansour, M., (2015): The Nurse's role in managing the psychological and emotional impact on women diagnosed with breast cancer. Clinical Nursing Studies, Vol. (3), No. (4), Pp. 1-100.

Williams, L., \& Hopper, D., (2011): Understanding Medical Surgical Nursing, nursing care of patients with cancer, $4^{\text {th }}$ ed., chapter 10, the United States of America, F. A. Davis Company, Pp.143-173. 